\title{
Documentos
}

SOBRE EL PACTO ANDINO - CARTA DIRIGIDA POR EL EX PRESIDENTE DE CHILE, SETTOR EDUARDO FREI, AL DIRECTOR DE "EL MERCURIO" DE SANTIAGO, EL $2 S$ DE AGOSTIO DE 1976

\section{Scñor Director:}

Durante estas últimas semanas en el diario da su dirección se han publicado numerosas noticias y' comentarios relativos al Pacto Andino. Asimismo, han aparecido cables cuyos textos revelan que existe cl riesgo evidente de que si se mantienen las posiciones sostenidas por los representantes chilenos nuestro país sea excluido del Pacto o que, como alternativa, los cinco países restantes concluyan uno nuevo en el cual Chile no estaría incluido.

Me parece un deber dar, en este caso, mi opinión sobre esta importante materia, porque el Pacto Andino turo su origen en conversaciones que sostuve el año 1965 en La Moneda con el Presidente electo de Colombia, señor Carlos Lleras Restrepo, y porque posteriormente me correspondió firmar en Bogotá, junto con los Presidente de Colombia y Venezuela y los representantes del Perú y Ecuador, a los cuales se agregó posteriormente Bolivia, las declaraciones y actas que le dieron nacimiento. El Gobierno' de Chile fue, además, un activo promotor en las negociaciones para llegar al Acuerdo de Cartagena y crear los organismos que le dieron vida operacional.

Las razones que movieron a estos seis países fueron entre otras, la necesidad de crear un mercado más amplio para desarrollar sus economías. Este mercado, que agrupa hoy a más de 70 millones de personas, con un producto superior a los 60 mil millones de dólares, está integrado por paises relativamente parecidos en su grado de crecimiento por lo cual habría "una competencia o intercambio entre iguales".

Como es sabido, la integración de países de muy distinto: grado de desarrollo resulta siempre difícil cuando no imposible, porque si los grados de poder o de fuexza y las industrias instaladas son muy desiguales, el débil queda en evidentes condiciones de inferioridad o sometimiento.

Los paises que conforman el Pacta Andino se juntaron para promorer una distribución equitativa y eficiente que compensara algunas diferencias, en especial a través de mecanismos como el llamado "Programas Sectoriales de Desarrollo Industrial".

Esturo también presente en el ánimo de quienes lo crearon, la convicción de que para un país en desarrollo $y$ aislado, los mercados externos no son de 
fácil acceso, muchos de elíos inestables y otros cautiros do las grandes empresas transnacionạles.

En tales condiciones resulta difícil exportar productos no tradicionales en forma conveniente y cstable para el país de origen.

La integración, en cambio, abre acceso a mercados mís amplios que el nacional, lo que permite aprovechar economías de escala en aquellos rubros para los cuales los mercados del resto del mundo son normalmente muy difíciles de penetrar, y permite a través de un arancel externo común defender a los productorea subregionales frento a la competencia exterior.

El pactc así concebido abre perspectivas muy amplias a los empresarios nacionales de los países integrantes, los cuales pueden contar con la información adecuada y la certidumbre de poder vender en un área más extensa, j'a que ella es sicte u ocho veces superior al mercado interno chileno.

Estas integraciones regionales son un camino que están siguiendo dirersos paises del mundo, convencidos de la necesidad de tener una base sólida y propia de operación para salì a luchar en los mexcados mundiales. Sí eso es necesario para naciones tan poderosas como las europcas, que forman una comunidad, algunas con poblaciones superiores a 60 millones de habitantes y con un producto nacional superior a Ios 200 mil millones de dólares, con cuánta mayor razón se justifica para un país qua con mucha optimismo no licga a los 8 ó 9 mil millones al cual se le ofrece la oportunidad de ingresar a un mercado entre iguales con incalculables posibilidades.

Algunos sostienen que el hecho de pertenecer al mercado andino dificultaria para el país abrirse paso hacia otros, to que carece de fundamento porquo esta integración no disminuye las posibilidades de intercambio con Argentina, que ha aumentado considerablemente, o con Brasil, Estados Unidos o con cualquier otro. Además, no hay duda también que el pertenecer al un mercado más amplio le da a este conjunto de paises una capacidad de negociación indispensable y que no pueden tener aisiados.

El argumento fundamental que se esgrime para condicionar la participación de Chile es que la Decisión 24 haría difícil, si no imposible, la llegada a nuestro país de inversiones extranjeras que le son necesarias. đa primera pregunta que surge es saber por qué log otros cinco países, que están recibiendo mayor inversión extranjera que Chile y con un ritmo de desarollo muy superior, estiman que esta decisión no los perjudica y mantienen el pacto.

La inversión extranjera encuentra en el Pacto Andino condiciones favorables y no desfavorables como se trata de hacer creer, porque siempre será más atractiva una inversión si ella cuenta con un mercado muchísimo mayor y se pacta con un conjunto de paises, lo que ofrece una mayor estabilidad que las convenidas con uno solo, y'a que así es más difícil modificar las reglas de juego establecidas. El mercado andino es evidentemente más atractivo que el rcducido a un solo pais, aunque éste prometa una apertura indiscriminada al inversionista extranjero en un mercado pequeño y aislado, con alta tasa inflacionaria. 
En cl mundo existe una experiencia generalizada que revela que normas muy farorables y una actitud en la prictica irrestricta para el ingreso del capital cxterno son de cludoso futuro, Generalmente cllas atraen a los inversionistas menos scrios, o que están dispuestos a correr riesgos y por eso mismo a obtener grandes utilidades a corto plazo. Ninguna de esas caracteristicas pucden ser convenientes para el país.

La principal norma de Ia Decisión 24 es la conversión gradual de Ias empresas cxiranjeras que desean operar en el mercado andino en empresas mixtas. Uno de los objetivos de esta participación es lograr el traspaso de los conocimientos técnicos y administiativos hacia el personal nacional, que queda asi asimilado a cmpresas radicadas en el país.

Hace 20 años o más la actitud del inversionista extranjero frente a la constitución de cmpresas mixtas no cra receptiva. Esa situación ha cambiado en el mundo entero $y$ hay mucho mayores posibilidacles de lograr la constitución de entidades que asocien al capital extranjero con capital y gestión nacional, ya sca pública o privada. Los cambios que se han operado en la economia interna cional en lugar de dejar fuera de época a la Decisión 24 la hacen hoy más vílida.

Por otra parte, la Decisión 24 es nlexible. Desde luego no busca la nacionali zación total ni inmediata, sino que busca llegar en un plazo de 15 ó 20 años a que $\dot{c} 15 \mathrm{l}$ por ciento del capital sea nacional o subregional, y cuanclo el socio es el Estado basta con un 30 por ciento de propicdad nacional.

La transferencia de capital en la empresa extranjera actual no tiene por qué haccrse con el retiro de ella a medida que aumente la participación nacional, pues el cambio en la propicdad puede realizarse por la vía del crecimicnto de las empresas.

La conversión de empresa extranjera en mixta se realiza en forma gradual, escalonada, $y$ para cumplir con clla bastaria que una proporción alta de las nuevas inversiones fuera de origen subregional. En este mundo de hoy un plazo de 15 o 20 años para operar en un mercado 7 u 8 reces más amplio que el nacional chileno, da posibilidades, seguridad y tiempo a las empresas.

A esto es necesario agregar que si se cstablecen industrias para vender sus productos en cualquier otra parte del mundo, fuera de los paíscs del árca andina no cae bajo esta disposición de constituirse en empresa mixta. Asi por ejemplo, inversiones que pudieran hacerse en el cobre para exportar a otras áreas no están afectadas a la nacionalización progresiva. Esto generalmente no sic dice.

En los recientes acuerdos de Boyacá se tomaron, por lo demás, dos importantes decisiones que modifican la 24 de una manera importante. La primera es que lás remesas de utilicladcs al exterior se aumentan del 14 al 20 por ciento $y$ la segunda que se reconoce que el capital proveniente de otros países de la sub región, o sea el capital subregional, sea considerado para todos estos efectos como capital nacional.

Siempre he sostenido que la Decision 24 u otras del Pacto pueden ser per- 
feccionadas. El año 1972 concurrí a un seminario en la Unirersidad de. Boston al cual asistían entre otros el ex Presidente de Colombía, don Carlos Lleras Restrepo; el ex ministro de Hacienda del Brasil y actual embajador en Londres, señor Roberto Campos; el señor Héctor Hurtado, actual ministro de Hacienda de Venezuela. En esa ocasión sosture que la Decisión 24- era fundamentalmente correcta, pero que la práctica habia scñalado que era necesario hacer algunas modificaciones $y$ entre ellas señalé estas dos que acaban de ser aprobadas en Boyacá. Esta opinión fue compartida por el ex Presidente Lleras y demás asistentes.

La Decisión 24 no está inspirada en ningún tipo de recelo en contra de la inversión extranjera, que es indispensable, y asi lo estiman los otros cinco países; pero todos ellos piensan que hay inversiones extranjeras farorables y otras inconvenientes. Algunos dogmáticos pretenden condenarlas en block, y otros, desde el lado opuesto, las idealizan y transforman en la única salvación. Ni lo uno ni lo otro. La inversión depende mucho de las condiciones y objetivos del pais receptor, de que se incorporen a él y colaboren a un desarrollo' nacional con características propias. Eso en el mundo se estŕ entendiendo cada yez más y todas las tendeucias caminan en ese sentido.

En cuanto al arancel extexior común, que es el otro punto en discrepancia, la propuesta de la Junta aprobada en Bocaýl por cinco países participantes del Pacto sin la asistencia de Chile significa una rebaja apreciable respecto de los niveles que regían en los paises andinos $y$ en particular en los bienes elaborados de consumo que estaban en excesa protegidos.

Todos sabemos que hubo una etapa de proteccionismo sin el cual no habria. nacido ninguna industria en Chile ni en los países que forman el Pacto Andino. Por lo demás, hasta las más grandes potencias en su etapa inicial de desarrollo han sido proteccionistas y lo son aún en muchos aspectos.

La continuación entre nosotros de esta protección inicial sin modificaciones, significó un error $\mathrm{y}$ con frecuencia abusos que es necesario corregir, pero cosa muy clistinta es pasar bruscamente de un extremo a otro.

La rebaja aprobada en. Boyacá tiende a llegar a niveles razonables que se han fijado en máximos de hasta 60 ó 70 por. ciento, salvo excepciones. El nivel planteado por los representantes del equipo económico chileno actual es de 35 por ciento. Los efectos negativos de una rebaja de este tipo en la inclustria nacional aún no se notan en toda su plenitud, pues faltan algunas por hacer y porque frente a la dramática situación económica y desocupación que enfrenta la industria nacional una competencia en esas condiciones con los países desarrollados sería de las más serias consecuencias.

Una desgravación gradual como la propuesta por los signatarios del Pacto, al país que más convendria seria justamente a Chile.

El empresario chileno ha sufrido dos experiencias económicas muy difíciles en scis años. En los primeros tres, inseguridad, paralización, "tomas", nacionaliza'ciones sin criterio alguno y dificultades en todo orden. En los últimos tres ha 
tenido seguridad, pero también restricciones muy severas, paralización del mercado, recesión y caida de producción en casi un 25 por ciento, como lo señala la propia Sociedad de Fonento Fabril, lo que es sin duda enorme. Por combatir la inflación hemos llegado a una situación que el pais bien conoce. El economista y primer vicepresidente del National City Bank, señor Irwing S. Friedman, recientemente escribio: "Por haberse convertido en una plaga global, a la inflación hay que combatirla mundialmente. Hay que combatirla no con desempleo ni crecimiento económico reducido $y$ niveles de rida más bajos, sina con may'or producción y mayor eficiencia".

En general las empresas chilenas han debido hacer frente a una menor demanda, a grandes deudas, altos intereses crediticios, están descapitalizadas y no han renovado sus equipos, pues están trabajando a un nivel bajo respecto a su capacidad. En esas condiciones, empresas debilitadas, sin base de consumo interno, atrasadas en cuanto a renovación de equipos, tendrán que entrar o competir con productores externos que durante los últimos años no han sufrido los avatares que ha sufrido Chile y han progresado relozmente en cuanto a tecnologia e instalaciones.

Este empresario además no dispone de crédito o dispone de un crédito escaso y a costos increíblemente altos, y así tendrá que enfrentarse a empresarios que disponen de amplios préstamos a bajisimo interés en comparación al nuestro y de mercados internos de enorme volumen, lo que abarata sus costos y les permite exportar excedentes.

No podia ser una oportunidad peor para ensayar un cambio de esta naturaleza. Si así ocurre, la crisis se ahondará agravándose la situación industrial y la desocupación, que afecta a profesionales, técnicos y obreros; lo que sin duda sería de catastróficos resultados no sólo sociales, que ya por si solos son los de mayor consideración, sino también económicos, pues reducirian aún más un mercado ya deprimido.

El argumento de que esto "favorece al consumidor" es, para decir lo menos, sorprendente, pues para que haya consumidores tiene que haber trabajo y por lo dcmás esas importaciones son para un grupo muy restringido que paga por ellas cualquier precio, coma se está viendo.

Un posible retiro de Chile-cualquiera que sean los nombres que se le dé al hecho- por mantener una posición rígida, ha conducido a que los otros paises consoliden una posición conjunta, la que no sólo es inconveniente sino muy grave para nuestro país.

Todo esto ocurre en un momento crucial del Pacto Andino. Muchas de sus acciones están en camino; muchas inversiones realizándose en todos los países y al mismo tiempo produciéndose diversas asignaciones de acuerdo con los programas sectoriales de desarrollo industrial.

Es alarmante pensar que Chile pueda quedar al margen de los otros circo paises que están dispucstos a avanzar con decisión y por su cuenta.

Los errores en este campo no son iguales a los que se cometen adentro del 
pais. Tienen mucho de irreversibles e irreparables. Las estructuras de producción dirigidas al mercado subregional se están conformando. Si en el futuro se quisicra volver, la situación de Chile sería muchisimo más dificil. Un dogmatismo que no considere el problema en su conjunto puede causarle un irreparable daño a la nación si se Ilega al extremo de la ruptura.

Retirarnos del mexcado andino donde formamos parte de una comunidad, de naciones, a las cuales estamos unidos por tantas razones, que sería obvio señalar, nos dejaria en una situación aún más aislada. Por eso creemos que este es un problema que debe ser meditado cuidadosamente antes de tomar una resolución que tendria implicancias no sólo económicas, sino políticas y otras de muy variada indole que no es del caso señalar aquí. Esta decisión, en consecuencia, no puede ser sólo de carácter económico-técnico sina debe ser una decisión política de la mayor trascendencia.

Seguramente se darán razones y explicaciones para combatir o desvirtuar lo que estoy afirmando. No seria la primera vez que esto ocurra; pero el hecho simple y claro es que la no permanencia de Chile en el Pacto constituiria un grave daño para el pais y para su futuro. 